\title{
Application of Distributed Wireless Chloride Sensors to Environmental Monitoring: Initial Results
}

\author{
Nick Harris, Andy Cranny, Mark Rivers, Keith Smettem, and Edward G. Barrett-Lennard
}

\begin{abstract}
Over the next 30 years, it is anticipated that the world will need to source $70 \%$ more food to provide for the growing population, and it is likely that a significant amount of this will have to come from irrigated land. However, the quality of irrigation water is also important, and measuring the quality of this water will allow management decisions to be made. Soil salinity is an important parameter in crop yield, and in this paper, we describe a chloride sensor system based on a low-cost robust screen-printed chloride ion sensor, suitable for use in distributed sensor networks. Previously, this sensor has been used in controlled laboratory-based experiments, but here we provide evidence that the sensor will find application outside of the laboratory in field deployments. We report on three experiments using this sensor; one with a soil column, one using a fluvarium, and finally on an experiment in a greenhouse. All these give an insight into the movement of chloride over small distances with high temporal resolution. These initial experiments illustrate that the new sensors are viable and usable with relatively simple electronics, and although subject to ongoing development, they are currently capable of providing new scientific data at high spatial and temporal resolutions. Therefore, we conclude that such chloride sensors, coupled with a distributed wireless network, offer a new paradigm in hydrological monitoring and will enable new applications, such as irrigation using mixtures of potable and brackish water, with significant cost and resource saving.
\end{abstract}

Index Terms-Chloride sensor, environment, hydrology, screen-printed sensor, wireless sensor network.

\section{INTRODUCTION}

O NE OF the major global challenges for the next 30 years is to provide an anticipated $70 \%$ increase in food supply [1]. Various factors have an influence on this [2], but significant yield gains are achievable from improved and extended irrigation techniques. Although irrigation allows higher yields, this comes at the expense of significant water usage, as it is reported that up to $50 \%$ of irrigation water

Manuscript received June 8, 2015; revised August 25, 2015; accepted September 25, 2015. This work was supported in part by the U.K. Biotechnology and Biological Sciences Research Council, under Grant BB/J021210/1 and in part by Worldwide Universities Network. The Associate Editor coordinating the review process was Dr. Deniz Gurkan.

N. Harris and A. Cranny are with the School of Electronics and Computer Science, University of Southampton, Southampton SO17 1BJ, U.K. (e-mail: nrh@ecs.soton.ac.uk).

M. Rivers is with the Institute of Agriculture, The University of Western Australia, Crawley, WA 6009, Australia.

K. Smettem is with the School of Civil, Environmental and Mining Engineering, The University of Western Australia, Crawley, WA 6009, Australia.

E. G. Barrett-Lennard is with the School of Plant Biology, The University of Western Australia, Crawley, WA 6009, Australia.

Color versions of one or more of the figures in this paper are available online at http://ieeexplore.ieee.org.

Digital Object Identifier 10.1109/TIM.2015.2490838 is wasted [3]. Salinity of soil solution is a parameter that has a direct impact on the yield of crops [4]. If salinity can be measured at a suitable temporal resolution, then irrigation applications using mixtures of brackish water and potable water become achievable [5], with a resulting saving in potable water supplies that can then be used elsewhere, or alternatively allowing an extension of irrigated land for the same potable water usage. As an example, the irrigation system of the Harvey Irrigation Area (HIA) in Western Australia uses several reservoirs to feed the pipe network, and the water quality from each reservoir is different. Currently, water rights can be traded within the HIA via an auction-based system or, more directly, between various agricultural and nonagricultural user groups, with one of the cost factors being the required water quality. The ability to use saline water under controlled circumstances here could both optimize water usage and lower the overall cost of water. There are significant price differences for the cost of water rights depending on the source of the water and, therefore, its quality, by a factor of at least $500 \%$ between the lower quality water and the higher quality [6]. In order to start making use of this, it is necessary to develop a sensor that not only allows measurement of the salinity, but is also low cost and rugged and has low-power requirements and a useful lifetime. Such a sensor, coupled with a suitable data transport and storage system, such as a wireless sensor network [7], would allow near real-time monitoring and control (with suitable actuators) [8] of irrigated land, giving significant socioeconomic impact.

In this paper, we discuss a chloride sensor that is low cost (of the order of a euro), has a long lifetime (at least a year [9]), and is low power (it is self-generating), thus potentially meeting all of the requirements needed for deployment in a distributed sensor network. As a precursor to such a deployment, it is useful to characterize the sensor connected to more suitable portable electronics than the laboratorygrade equipment used previously and to verify that the results achieved in the laboratory can be replicated in less controlled field environments. The initial work in this paper was reported at SAS2015 in Croatia [10], but this paper extends the previous work by adding to the detail reported and also reports on a further longer term deployment in a greenhouse over a period of 12 days.

Currently, salinity measurements are usually performed by grab sampling and then analysis in a laboratory [11] or by the use of large, expensive, and isolated salinity loggers. Both of these approaches are carried out infrequently (due to cost and inconvenience) and only give a snapshot in time or 


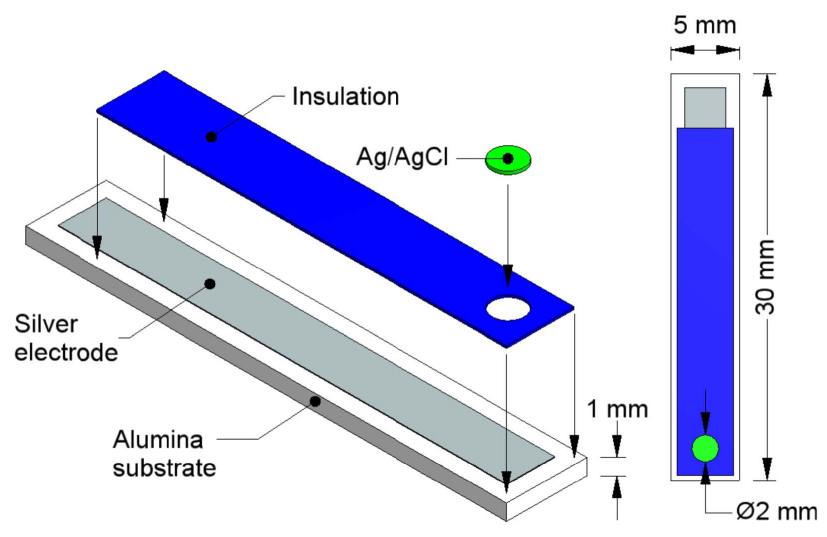

Fig. 1. Schematic showing individual layers and dimensions of a sensor.

for specific locations, potentially missing important transient or distributed events. Alternatively, conductivity can be used as a proxy for salinity [12], but this makes the assumption that the conductivity is only affected by changes in salinity, whereas in reality, there are many potential interference signals (such as application of fertilizer). Thus, there is a requirement for a low-cost salinity sensor, which would allow interesting and high-impact applications to be implemented, as in the examples above.

\section{SENSOR DESCRIPTION}

The recent work at the University of Southampton has produced a prototype sensor capable of directly measuring chloride concentrations [9]. It is a potentiometric sensor, meaning that it generates an electrical potential proportional to the local chloride concentration, making it inherently of low power consumption. It is manufactured by an industrystandard screen printing process, which makes it low cost, and it has a lifetime comparable with typical crop-growing seasons.

The sensors used for these experiments have been reported previously [9] and are undergoing continuing development with the latest generation incorporating an integrated reference electrode [13], but these were not available for the tests reported here. The sensor structure consists of a silver layer screen printed onto an alumina substrate, as shown in Fig. 1. A patterned insulating layer is then printed over the majority of the silver layer, which defines the active area of the electrode structure as well as leaving a short solderable-free end for electrical connection. In these sensors, the exposed silver layer is electrochemically chloridized to produce a silver chloride layer on top of the silver electrode, rather than screen printing a separate silver chloride layer. The resulting structure generates a potential that has a logarithmic response to chloride ion concentration. The response is governed by the Nernst equation, which predicts a theoretical sensitivity of approximately $-59.2 \mathrm{mV} / \mathrm{pCl}$ at a temperature of $298 \mathrm{~K}$, as given by

$$
E=E_{o}-0.0592 \log \left(C_{\mathrm{Cl}}\right) .
$$

Here $E$ is the measured electrode potential $(\mathrm{V}), E_{o}$ is the offset potential $(\mathrm{V})$ and $C_{\mathrm{Cl}}$ is the chloride ion

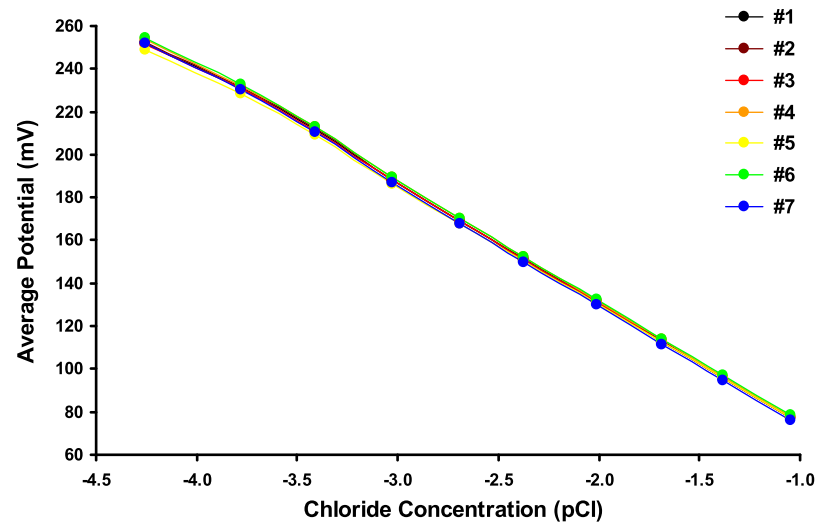

Fig. 2. Typical sensor calibration response and repeatability.

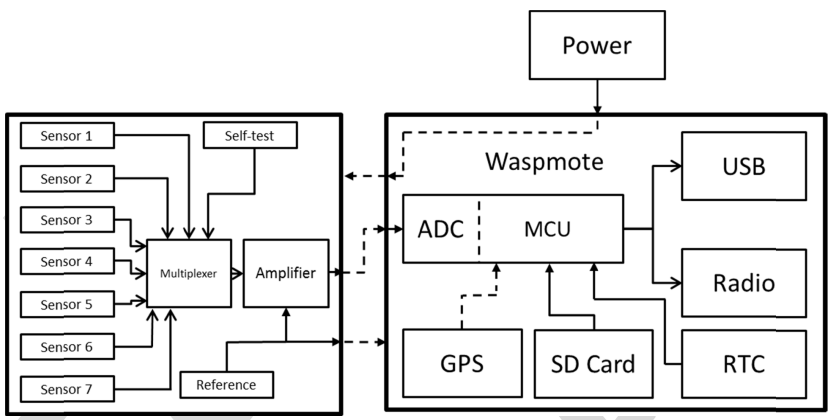

Fig. 3. Schematic showing electronics architecture.

concentration (M). Since the sensors are potentiometric, they need to be measured with respect to a reference potential. Accordingly, all measurements reported here were made with respect to a commercial $\mathrm{Ag} / \mathrm{AgCl}$ reference electrode (VWR GelPlas, $3.5 \mathrm{M} \mathrm{KCl}$ ).

The sensors were calibrated using known concentrations of potassium chloride solution and Fig. 2 shows a typical response set for a batch of seven sensors. It can be seen that the variability between sensors is very low, with sensitivities typically close to $55 \mathrm{mV} / \mathrm{pCl}$ [9]. The calibration shown in Fig. 2 was carried out at room temperature $\left(25^{\circ} \mathrm{C}\right)$, but it is noted that the response is affected by temperature. Thus, compensation was applied for the experiments reported, but it was only significant for the greenhouse experiment, since the temperature ranged between $13{ }^{\circ} \mathrm{C}$ at night to $35{ }^{\circ} \mathrm{C}$ during the day. This was done by measuring the response of the sensors when immersed in several known sodium chloride concentrations $(1000,500,250,125$, and $62.5 \mathrm{mM})$ at $25^{\circ} \mathrm{C}$, and also at $50{ }^{\circ} \mathrm{C}$, and then assuming a linear regression for variation with temperature for a given chloride concentration. Air temperature in the greenhouse was available from the greenhouse monitoring system, which could then be used to index the compensation after the sensors had had their output converted from a raw voltage to a concentration.

\section{SEnsor Electronics}

The logging electronics were custom built for the sensors. The system consisted of an analog processing board, a digital 
board, and a robust water-proof housing. Fig. 3 shows the system architecture, with an analog board and a digital system. The analog board allowed up to seven individual sensors to be connected and measured against a single reference, with an 8th channel being fed with a fixed voltage to act as a form of self-test for the analog part of the system and to monitor the status of the systems power supply. Each sensor was measured individually and sequentially through an analog multiplexer. The signal was then amplified by a gain factor, which could be varied to allow for different expected dynamic ranges. The reference here is the commercial reference electrode, giving a fixed potential against which the sensor electrodes can be measured.

The digital board in this case was based on a Waspmote node, which uses an Atmel microcontroller [14], similar to an Arduino. This platform already has interfaces for common radio systems such as IEEE 802.15.4 or Global System for Mobile communication, and also has an Secure Digital (SD) card interface. Programming was done via an USB connection to a PC. The Waspmote was powered by an $1150-\mathrm{mAh}$ rechargeable battery, which in this case is recharged by connecting the system to a PC via the USB cable. The Waspmote board controlled the power to the analog board through a switched output pin and used three other pins to control the multiplexer channel selection. Data were digitized from the analog board using an on-board A/D that has a 10-bit resolution. These data were then scaled, time stamped, and then either assembled into a data packet for radio transmission or stored on the SD card. The system was sent to sleep between readings, for a predetermined length of time, depending on the application, waking up under the control of an interrupt generated by a built-in real-time clock (RTC).

Although the power consumption of the system is important, it is the sensor power consumption that is of most interest here, and the sensors themselves, being potentiometric, actually generate their own potential. The measuring system thus becomes the defining aspect and many low-power solutions are available. In this case, the Waspmote has an advertised sleep current in the extended sleep mode of $62 \mu \mathrm{A}$ and consumes $9 \mathrm{~mA}$ when active. Using peripheral functions will then add to this consumption. The measured consumption of the current system is $25 \mathrm{~mA}$ on average when logging with most of the extra current being used in writing data to the SD card and $125 \mu \mathrm{A}$ whilst asleep. Currently, the active measurement loop takes $2 \mathrm{~s}$ to complete, but this could easily be reduced as we are writing extraneous text to the memory card to aid data processing, and are also using a light-emitting diode to indicate correct operation. This gives an energy per measurement cycle of $3.3 \mathrm{~V} \times 25 \mathrm{~mA} \times 2 \mathrm{~s}=165 \mathrm{~mJ}$. It is then possible to estimate battery life assuming that all of the $1150-\mathrm{mAh}$ capacity is available. For example, continuous operation should yield a battery life of 92836 2-s cycles (or about 2.1 days) as notionally, the $3.7 \mathrm{~V}$ battery contains $3.7 \times 1.15 \times 3600=15318 \mathrm{~J}$. If the system sleeps for $5 \mathrm{~s}$ giving a duty cycle of $2 / 7$, the overall battery life is just under 7.5 days. Similarly, a sleep period of $28 \mathrm{~s}$ would give a lifetime of 30 days. Such figures were more than adequate for current testing, but future developments will continue to reduce the

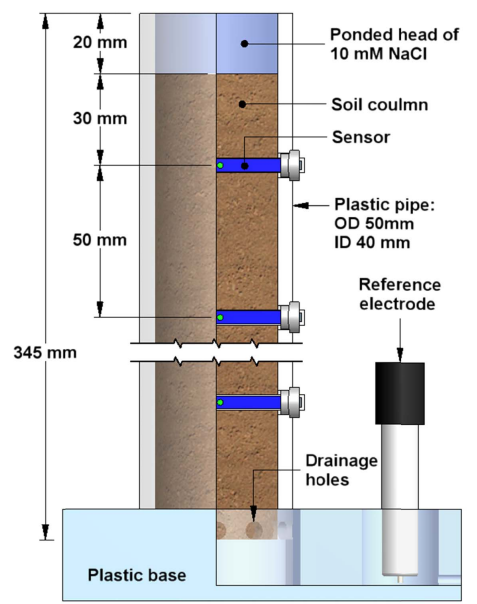

Fig. 4. Arrangement for soil column experiment (with cutaway view).

system power consumption. As sleep periods become longer, battery leakage and sleep currents become the limiting factor. The potential lifetime of a system is a function of the capacity of the energy source and the overall consumption.

For multiple data loggers operating at the same time, it was necessary to synchronize the clocks of the loggers. This was achieved by running a separate program that extracted the time from a GPS module that was temporarily installed into each logger and using this to set the RTC, with the RTC accuracy being stated as $\pm 2 \mathrm{ppm}$ or $0.16 \mathrm{~s} /$ day. Finally, the electronics were housed in a water-proof box, with the sensors grommeted through the casing. The sensors were on 1-mcables and so the sensing points could be up to $\pm 1 \mathrm{~m}$ away from the logger. Although it was possible to construct elaborate networks with the Waspmote, for these experiments, the system was either used as a simple remote logger or as a star network.

\section{EXPERIMENTS}

Three experiments were performed with the logger/sensor modules to establish the usefulness and practicality of being able to measure chloride at multiple points in situ:

1) single logger module with multiple sensors distributed at different depths in a soil column;

2) multiple logger modules, each with multiple sensors linearly deployed in a fluvarium;

3) single logger module installed in a practical environment (a greenhouse) to demonstrate the ability to perform longer term tests.

\section{A. Single Logger Module With Multiple Sensors Distributed at Different Depths in a Soil Column}

Although similar to work presented in [9], this experiment differs in that it demonstrates that the sensors can be used with simpler portable measuring systems, which is a step toward their use in field situations. In the previous work, a National-Instruments-based LabView system was used to $\log$ the data of the sensors. The experiment reported here is a more rigorous version and was designed to show that the system was able to perform similarly to the previous work and demonstrate the value of making real-time measurements to 


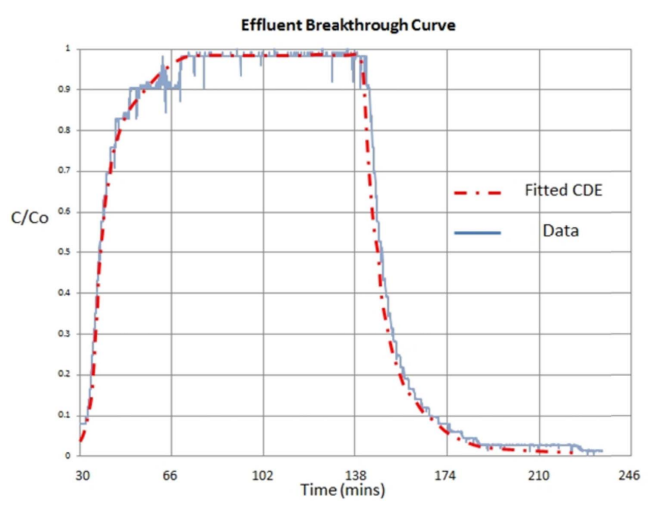

Fig. 5. Measured and predicted breakthrough curve for sensor 7 .

validate conventional modeling predictions, which will allow other situations to be modeled with confidence. It was designed to illustrate the transport of chloride though a repacked soil column under steady-state saturated flow. The experimental setup is shown in Fig. 4.

One logger was used with six sensors placed in the soil column at 50-mm vertical intervals from an initial depth of $30 \mathrm{~mm}$ from the surface and the reference located in the drainage flow. Channel 7 was at the top of the column and Channel 2 at the bottom. In this case, data were stored on the SD memory card and also sent wirelessly using IEEE 802.15.4 to a local computer for real-time monitoring through a MATLAB GUI. Sensor potentials were logged at a rate of one reading per sensor every 3 seconds, with each reading being the average of 10 successive samples.

A steady-state saturated flow regime of $510 \mathrm{mLh}^{-1}$ into a core of $1256-\mathrm{mm}^{2}$ cross section was established, giving an inflow flux of $406 \mathrm{Lh}^{-1} \mathrm{~m}^{-2}$. A ponded head of $20 \mathrm{~mm}$ was maintained at the surface with an initial background solution of $10 \mathrm{mM}$ chloride solution as $\mathrm{NaCl}$. A chloride pulse was then supplied by switching to a $100 \mathrm{mM}$ solution of $\mathrm{NaCl}$ and subsequently switching back to the $10 \mathrm{mM}$ background solution after $0.25 \mathrm{~L}$ had been supplied to the column. As an example, Fig. 5 shows the normalized measured breakthrough curve for the top sensor, together with the theoretical curve as given by convective-dispersive modeling using an updated excel version of the CXTFIT program [15]. Not only were the data well matched, but also, importantly, the mass recovery of chloride was $100 \%$ of the applied chloride.

Fig. 6 shows the results from all sensors, giving absolute concentration, and the progression and dispersion of the chloride pulse can be seen clearly. Some interesting observations can be made and most noteably that there was evidence of preferential flow pathways though the column. Some sensors did not respond in the manner that theory would anticipate, even though great care was taken in the packing of the core. It would be expected that all sensors would respond similarly, but with a time delay between them, this was not particularly evident. For example, the trace for Channel 5 (with a rapid smooth rise and a rapid fall back to background levels) shows a profile closer to that of Channel 7 (at the top of the column) than to the adjacent channels, which showed longer pulse transitions.

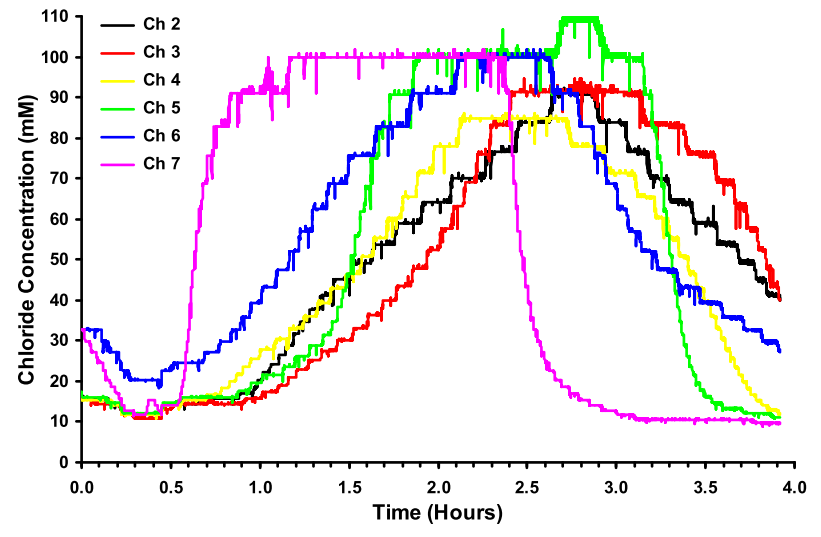

Fig. 6. Calibrated data from sensors positioned in the soil pipe.

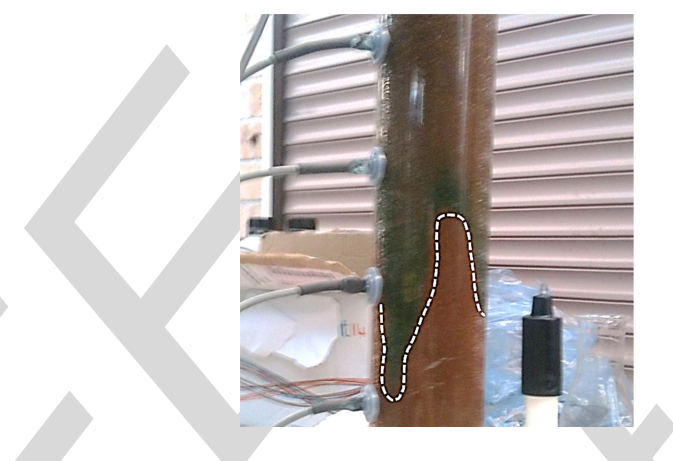

Fig. 7. Photograph of a rig showing a preferential path, enhanced by dye.

It can also be seen that Channel 4, located lower in the column, starts to respond slightly before Channel 5 , which is higher in the column. This was probably due to the presence of preferential paths for chloride movement through the column. These preferential paths were verified by separate experiments using salt pulses mixed with visible dye in a transparent column, where it was seen that different paths were apparent for salt transport and that sensors only responded when the dye-laden salt reached the sensor element. An example of the paths taken by dye laden salt can be observed in Fig. 7, where blue dye was added to the salt pulse. It can be seen that the movement through the column is uneven, despite great care being taken to pack the column. This illustrates the interesting results that these new sensors can reveal in even simple experiments such as this, and also indicates that conventional point measurement data need to be interpreted carefully.

\section{B. Multiple Logger Modules, Each With Multiple Sensors Linearly Deployed in a Fluvarium}

A fluvarium is a form of river simulator and in this case consists of a long channel $(20 \mathrm{~m})$, which had previously been filled with a stream sediment. This was used as a representative stream environment. The slope of the fluvarium was adjustable and the water flow rate could be controlled by a gated pump and measured at the outflow by the use of a flume. Fig. 8 shows a photograph of the fluvarium along its length. The sensors can be seen inserted into the river bed at 


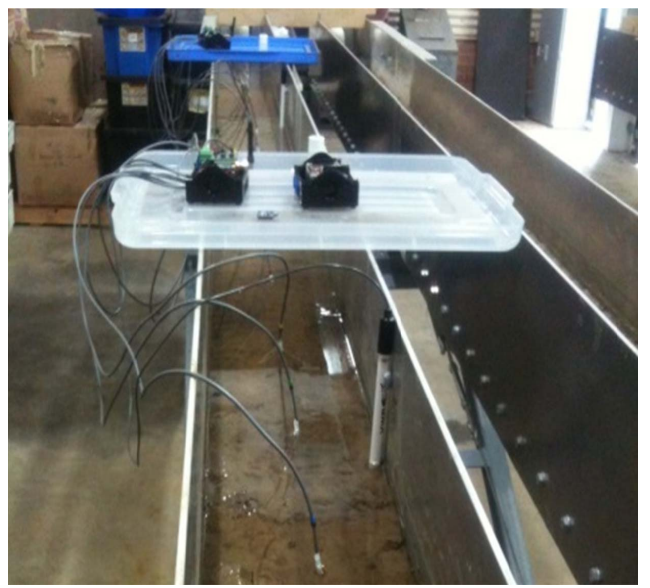

Fig. 8. Photograph showing part of the fluvarium with installed sensors.

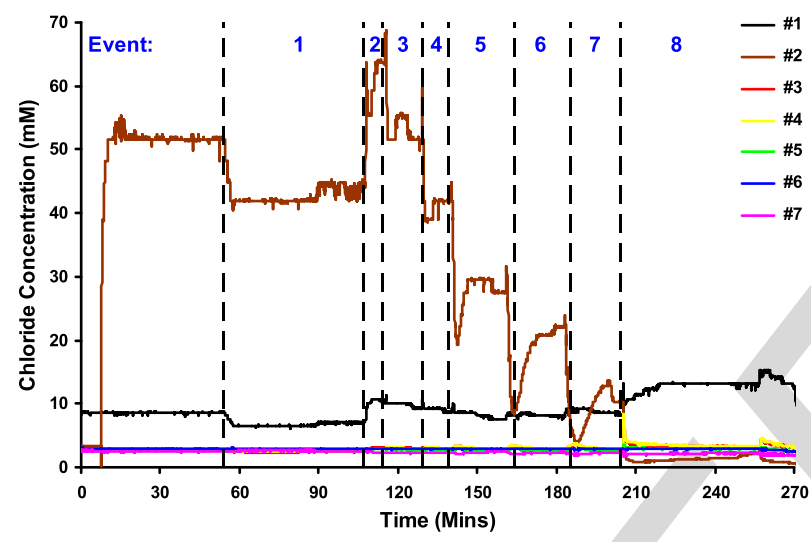

Fig. 9. Results from embedded sensors. Sensor 2 is in the inlet pool.

various locations. For the experiment reported here, the sensors were placed at $30-\mathrm{cm}$ intervals along the fluvarium length. Two sets of sensors (14 sensors) were used to give longitudinal measurements. A third set of sensors were colocated with the downstream sensors but were located in the surface water flow rather than being embedded in the bed sediment. The embedded sensors were inserted to a depth of $20 \mathrm{~mm}$.

The fluvarium was allowed to soak overnight in tap water with a base concentration of $10 \mathrm{mM}$ chloride solution, with no slope and no flow. A $100-\mathrm{mL}$ volume of $100 \mathrm{mM}$ chloride solution was added at the fluvarium inlet with no flow into the fluvarium, and this was allowed to pool at the inlet. A sensor (sensor 2) was placed near the downstream end of this pool as a reference, and it can be seen (Fig. 9) that the added solution was diluted by the water already in the fluvarium to give a reading of about $52 \mathrm{mM}$. The other sensors shown in Fig. 9 are those located in the river bed, moving downstream in numerical order. All of these showed very low levels of chloride, except for sensor 1, which was located very near the inlet pool. This is itself an interesting result as this is indicating that even though the river bed was wet, there was very little diffusion of chloride through the bed to the depth of the sensors over the course of the experiment, except at the point near the inlet pool. This is reasonable because the

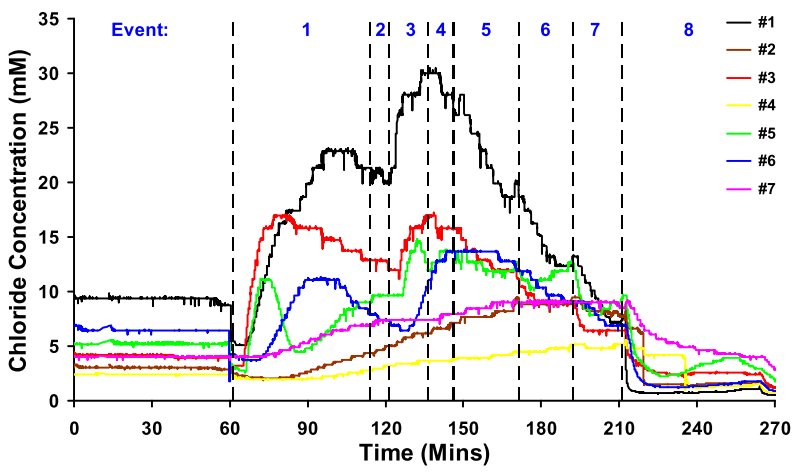

Fig. 10. Results from surface flow sensors.

TABLE I

DESCRIPTION OF FLUVARIUM EVENTS

\begin{tabular}{|l|l|l|}
\hline Event & Time (mins) & Description \\
\hline 1 & 54 & Fluvarium tilted \\
\hline 2 & 107 & $200 \mathrm{~mL}$ water added \\
\hline 3 & 114 & $200 \mathrm{~mL}$ water added \\
\hline 4 & 129 & $200 \mathrm{~mL}$ water added \\
\hline 5 & 139 & $400 \mathrm{~mL}$ water added \\
\hline 6 & 164 & $600 \mathrm{~mL}$ water added \\
\hline 7 & 185 & $1,000 \mathrm{~mL}$ water added \\
\hline 8 & 204 & Flume turned on \\
\hline
\end{tabular}

inlet pool was the point at which the chloride concentration was highest for longest and also the point at which there was most flow momentum as this is where new fluid was added. At about $50 \mathrm{~min}$, the gradient of the fluvarium was increased to encourage a slow drain flow away from the inlet. Periodically, samples of tap water were added to the inlet pool from a flask to provide impetus. The pulsatile nature of this method of introducing flow is apparent from Fig. 9. These events are listed in Table I.

All these events are shown in Fig. 9 and it can be seen that the sensor in the fluid in the inlet pool responded very quickly. Sensor 1 (embedded in the river bed, but nearest the inlet) also showed a small response. There was a response as the fluvarium was tilted very slightly and sensors 1 and 2 showed a decrease in concentration. This is intuitively unexpected but can be explained by the relatively poorly mixed inlet solution starting to move toward the outlet and move downstream or more local mixing of the original solution around the surface of this sensor. This movement effect is emphasized as the first volume of water was added at $107 \mathrm{~min}$. The addition of the water pushed the higher concentration further down the fluvarium as a pulse as is shown by sensor 2. Other additions are then seen to indicate a reduced concentration as the chloride volume was replaced by a more dilute solution as again pulses are pushed further down the fluvarium. These results indicate that the chloride pulse was exhibiting stop/start motion down the fluvarium under the direct influence of the addition of the extra water, as the slope was not enough to establish a meaningful flow for the volumes involved. When the fluvarium was turned on at about 200 min, a steady flow 


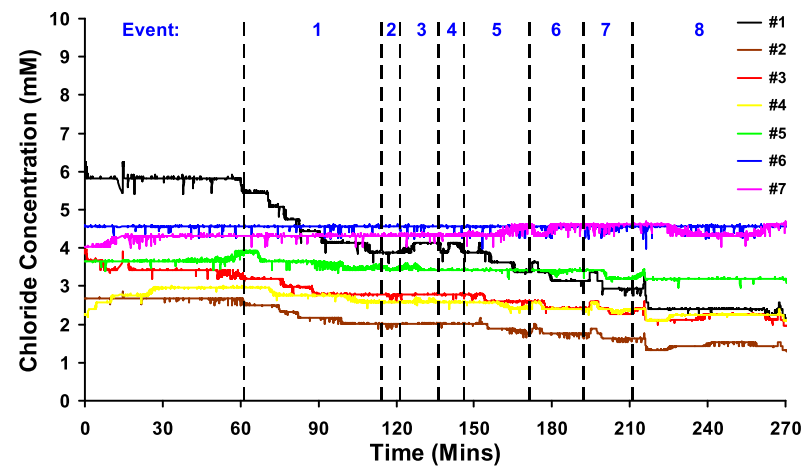

Fig. 11. Results from sensors embedded within the fluvarium sediment.

of water established itself after a few minutes and sensor 2 then showed a similar reading to the other sensors, indicating that the chloride in the inlet pool had been flushed. Sensor 1's output continued to rise as chloride was pushed or diffused through the river bed under the influence of the now constant input stream, but started to fall as the experiment finished.

Fig. 10 shows the response of the surface flow sensors located further down the fluvarium. The dotted lines show the events of Table I. The picture is less clear here. There was evidence that sensors 1,3 , and 6 were responding similarly, showing an increase in chloride concentration with time before tailing off. This is commensurated with the initial chloride pulse moving down through the surface flow of the fluvarium, being initially driven by the tilting and establishing a concentration gradient, as the sensors peaked in inverse order of distance between 60 and 100 min. Later responses were driven by the water events with a time delay, with the delay being related to distance, but it is difficult to quantify this. The other sensors responded slowly to the changing chloride environment, but correlating individual responses to a particular event is difficult.

Upon investigation, it was apparent that under these slow flow conditions, and due to the fact that the river bed in the fluvarium was not completely flat, a preferred meandering surface flow path was being established in the fluvarium. Visual inspection revealed that sensors 1,3 , and 5 were positioned in that flow. Other sensors were not in the apparent preferred flow path and so were responsive to different driving functions. A third set of colocated sensors were also measured, with these being embedded $20 \mathrm{~mm}$ deep in the river bed. This third set of sensors showed little variation from baseline over the time of the experiment, similar to sensors 3 to 7 in Fig. 9. These results are shown in Fig. 11. Although a negative result, this does show that in this river bed structure, diffusion of chloride from the flow to the bed was very slow, which in itself is an interesting result.

\section{Single Logger Module With Multiple Sensor Nodes Installed in a Practical Environment (a Greenhouse)}

In this experiment, a single logger with seven sensors was installed in a greenhouse. The seven sensors were wired to a frame and suspended in a 30-L box of sandy soil at a depth of $1 \mathrm{~cm}$, as shown in Fig. 12. One other sensor was buried to

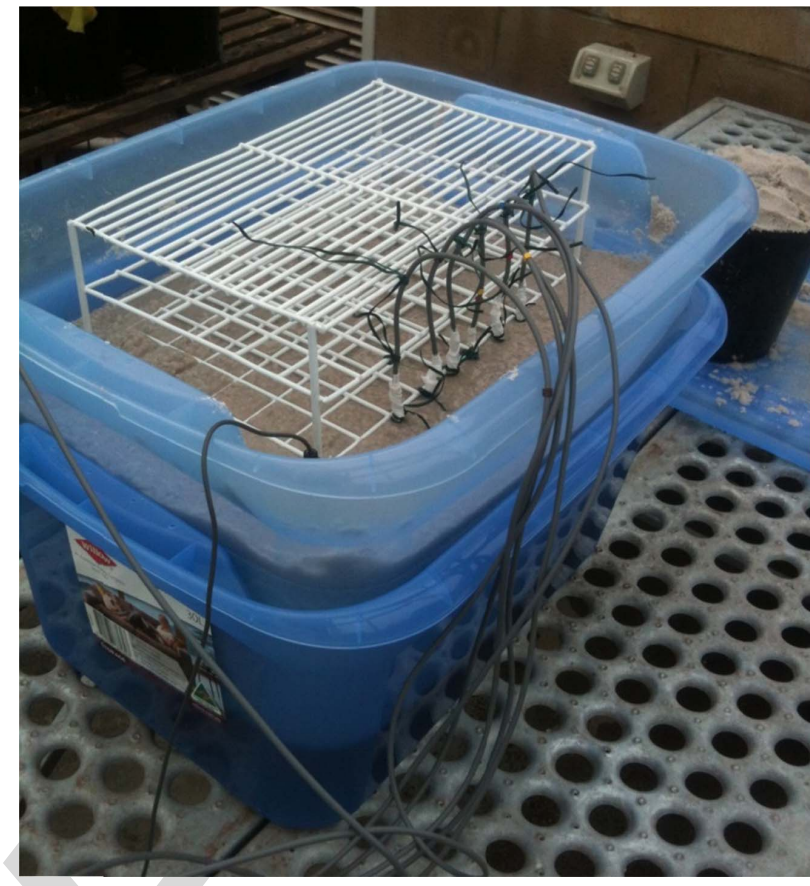

Fig. 12. Sensors mounted in a box of sandy soil in a greenhouse.

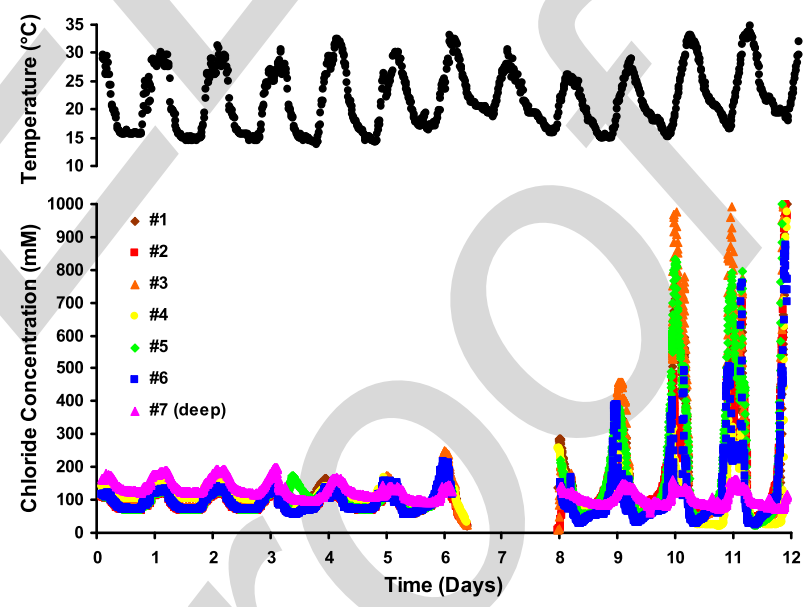

Fig. 13. Concentration data from the greenhouse mounted sensors together with ambient temperature.

a depth of $10 \mathrm{~cm}$. The box was saturated with the $100 \mathrm{mM}$ $\mathrm{NaCl}$ solution from below. Holes were drilled in the base of the box and the solution was allowed draining out. Sensors were logged at 5-min intervals. The electronics were contained in a polystyrene box to act as a temperature buffer to minimize effects of temperature on the electronic system.

The data were collected from the logger and Fig. 13 shows all the data over the duration of the experiment. It is apparent that as the soil dried out, the concentration of salt in the soil solution increased, but even over the first few days, there was a definite diurnal pattern as indicated by the ambient air temperature data. This raises the question as to whether this was a real effect or a temperature related effect, despite the temperature calibration applied. We can confirm that this was not temperature related, as an increase in temperature had 
the effect of increasing the raw sensor voltage for a given concentration, as established in our temperature calibration experiments. This implies a lower apparent concentration if no temperature compensation was applied. In our case, the raw voltage decreased with increasing ambient temperature, which would apply an error to act to reduce the apparent concentration. Thus, this diurnal variation would be de-emphasized when looking at the raw data.

With reference to Fig. 13, we can observe the definite diurnal variation though initially all traces followed the same pattern, indicating no relative difference in concentration between sensors. However, after about day 5, the shallow sensors started to deviate from the deep sensor response. At this point (day 6), the battery in the data logger failed. It was replaced two days later and the following four days show an increased divergence between the deep sensor and the shallow sensors. This corresponded to the surface soil drying out and a big increase in salt concentration in the remaining soil solution. Overnight this concentration was reduced, most likely by the capillary movement upward of moisture from deeper down or from condensation onto the surface from the atmosphere.

What is particularly marked is the rapid increase in concentration and the very large range of concentration that was possible over just a 24-h period as the soil dried out, ranging from $\sim 100$ up to $\sim 1000 \mathrm{mM}$. Once again, we can question whether this is a real effect, as the conductivity between the sensors and the reference electrode may have been affected by changes in soil moisture. Again if this was significant, it would act to reduce the apparent concentration as the voltage measured would increase. However, we actually saw a decrease in voltage measured, which implies that conductivity was still good. Thus, we can conclude that we are seeing evidence of significant variations in chloride concentration over a 24-h period, which is dependent on depth in the soil.

\section{Conclusion}

These initial trials of chloride sensors in all of these environments allow some interesting observations to be made and demonstrate the need for such sensors. First, we conclude that the sensors are usable in such environments and allow real-time measurements of chloride concentration in both fluid and wet soil environments, although significant variations in temperature do need to be compensated for. It is also apparent that calibration for absolute measurements for these sensors still requires work, but fundamentally, they operate well, and in their current state of development, they have already been providing interesting scientific data. Second, the simple experiments reported here illustrate the care needed in interpreting spot measurements in a distributed environment. Even sensors positioned a few centimeters away from a preferred flow path will give results significantly different from those obtained for sensors positioned in the preferred flow. This was evident in both the slow moving soil column experiment, where great efforts had been made to homogenize the soil packing and the more random system of the fluvarium river bed surface. This point was also emphasized in the greenhouse experiment, where the depth of the sensor was shown to be significant, as well as the relative time when the measurement was taken. This also illustrates the multiscale nature of measurements in the environment, with the surprising result that measurements can change by an order of magnitude just depending on the time of day the measurement was taken. Third, although in the fluvarium system, surface flows exhibited significant chloride concentrations, this was not necessarily evidenced even at low depths of $20 \mathrm{~mm}$ in the river bed, except very near the source of chloride. The greenhouse experiment also demonstrated the significant variation in local concentration over relatively small spatial distances.

Thus, we conclude that these chloride sensors and associated electronics offer an opportunity to measure and track shortterm chloride events in both flowing water and more static soil environments. They also offer the opportunity to measure at the same positions for longer periods of time, in contrast to the expensive, time-consuming, and often inaccurate alternative of grab sampling. The need for distributed sensors across a wide area is established and the dangers of extrapolating measurements from a point measurement are illustrated. Thus, it is concluded that these sensors, being low power and low cost, can make a significant contribution to understanding the mechanics of chloride movement though the environment and, when coupled with a distributed network, offer these results over a significant temporal and spatial scale previously unavailable.

Future work will concentrate on improving the calibration methods, particularly using the integrated technology reported in [13] and adding these sensors to a wireless network infrastructure to allow wider scale test deployments.

\section{ACKNOWLEDGMENT}

This work was funded by the UK's Biotechnology and Biological Sciences Research Council (BBSRC), grant number BB/J021210/1, and by the Worldwide Universities Network (WUN). The authors would also like to thank A. Shetta who developed the initial prototype data logger as part of his MSc degree at the University of Southampton under the supervision of N. Harris and A. Cranny.

\section{REFERENCES}

[1] FAO. (2009). How to Feed the World in 2050. [Online]. Available: http://www.fao.org/fileadmin/templates/wsfs/docs/expert_paper/How_to _Feed_the_World_in_2050.pdf, accessed Aug. 10, 2015.

[2] N. D. Mueller, "Closing yield gaps through nutrient and water management," Nature, vol. 490, no. 7419, pp. 254-257, 2012.

[3] M. Rivers, N. Coles, H. Zia, N. R. Harris, and R. Yates, "How could sensor networks help with agricultural water management issues? Optimizing irrigation scheduling through networked soil-moisture sensors," in Proc. IEEE Sensors Appl. Symp., Zadar, Croatia, Apr. 2015, pp. 1-6.

[4] N. Katerji, J. W. van Hoorn, A. Hamdy, and M. Mastrorilli, "Salinity effect on crop development and yield, analysis of salt tolerance according to several classification methods," Agricult. Water Manage., vol. 62, no. 1, pp. 37-66, 2003.

[5] J. D. Rhoades, "Use of saline water for irrigation," California Agricult., vol. 38, no. 10, pp. 42-43, Oct. 1984. [Online]. Available: https://ucanr edu/repositoryfiles/ca3810p42-72379.pdf, accessed Sep. 28, 2015.

[6] Harvey Water Water Trading. [Online]. Available: $\mathrm{http} / / / \mathrm{www}$. harveywater.com.au/water_trading.asp?watertradingid=5, accessed Sep. 28, 2015.

[7] Aqeel-ur-Rehman, A. Z. Abbasi, N. Islam, and Z. A. Shaikh, "A review of wireless sensors and networks' applications in agriculture," Comput. Standards Interfaces, vol. 36, no. 2, pp. 263-270, 2014. [Online]. Available: http://dx.doi.org/10.1016/j.csi.2011.03.004 
[8] H. Zia, N. R. Harris, G. V. Merrett, M. Rivers, and N. Coles, "The impact of agricultural activities on water quality: A case for collaborative catchment-scale management using integrated wireless sensor networks," Comput. Electron. Agricult., vol. 96, pp. 38-126, Aug. 2013.

[9] A. Cranny, N. R. Harris, M. Nie, J. A. Wharton, R. J. K. Wood, and K. R. Stokes, "Screen-printed potentiometric $\mathrm{Ag} / \mathrm{AgCl}$ chloride sensors: Lifetime performance and their use in soil salt measurements," Sens. Actuators A, Phys., vol. 169, no. 2, pp. 288-294, Oct. 2011.

[10] N. Harris, A. Cranny, M. Rivers, and K. Smettem, "Applications of a wireless chloride sensor in environmental monitoring," in Proc. IEEE Sensors Appl. Symp., Zadar, Croatia, Apr. 2015, pp. 1-5.

[11] D. L. Corwin and S. M. Lesch, "Protocols and guidelines for fieldscale measurement of soil salinity distribution with ECa-directed soil sampling," J. Environ. Eng. Geophys., vol. 18, no. 1, pp. 1-25, 2013.

[12] D. L. Corwin and S. M. Lesch, "Apparent soil electrical conductivity measurements in agriculture," Comput. Electron. Agricult., vol. 46, nos. 1-3, pp. 11-43, Mar. 2005.

[13] A. Cranny, N. R. Harris, and N. M. White, "Screen-printable porous glass: A new material for electrochemical sensors," J. Mater. Sci., Mater Electron., vol. 26, no. 7, pp. 4557-4564, Jul. 2015.

[14] Libelium. Libellium Website. [Online]. Available: http://www.libelium.com/products/waspmote/, accessed Oct. 22, 2015.

[15] N. Toride, F. J. Leij, and M. T. Van Genuchten, "The CXTFIT code for estimating transport parameters from laboratory or field tracer experiments," U.S. Salinity Lab., United States Dept. Agricult., Agricult. Res. Service, Riverside, CA, USA, Res. Rep. 137, Version 2.0, 1995.

Nick Harris received the Ph.D. degree from the University of Southampton Southampton, U.K., in 1997.

$\mathrm{He}$ is currently an Associate Professor with the Department of Electronics and Computer Science, University of Southampton. He is the Co-Founder of Perpetuum Ltd., Southampton, the world's leading vibration energy harvesting company. He has authored over 180 publications and patents in electrochemical sensors, wireless sensor networks, biosensors, energy harvesting, microfluidic systems, and microsystem process development. His current research interests include machine-leaning approaches for distributed sensor systems, ion-selective electrochemical sensors, and novel environmental energy harvesters.

Dr. Harris is a member of the Institution of Engineering and Technology, a Chartered Engineer, and the Director of ECS Partners.

Andy Cranny received the Ph.D. degree in electronics and computer science from the University of Southampton, Southampton, U.K., in 1992.

$\mathrm{He}$ is currently a Senior Research Fellow with the Faculty of Physical Sciences and Engineering, University of Southampton. His current research interests include the development of environmental sensors and the development of autonomous systems for home-based physical rehabilitation.
Mark Rivers is currently a Research Professor with the Institute of Agriculture, University of Western Australia, Crawley, WA, Australia, and the Director of ClearWater Research and Management Pty. Ltd., Mandurah, WA, Australia. His principal areas of expertise lie in developing the relationships between land management practices and catchment water quality. The majority of his professional experience has been gained working within threatened ecosystems prone to eutrophication and toxic algal blooms. He has extensive experience in the development of environmental risk scenarios and on the analysis of the likely environmental, social, and economic effects of adverse impacts on major water bodies.

Mr. Rivers is a member of the Environment Institute of Australia and New Zealand, a Qualified Lead Auditor of Environmental Management Systems, and a Certified Environmental Practitioner. He has represented the state of WA at senior diplomatic-level meetings concerning water quality protection in Turkey, Italy, U.K., and the USA.

Keith Smettem received the Ph.D. degree from Sheffield University, Sheffield, U.K., in 1982.

He is currently a Professor of Environmental Engineering with the Department of Civil, Environmental and Mining Engineering, University of Western Australia, Crawley, WA, Australia. He has authored over 200 publications and patents in hydrology, soil physics, plant water relations, and environmental engineering. His current research interests include ecohydrologic responses to climate change, development of woody perennial feedstocks for bioenergy generation, development of field methods for measurement of soil physical properties, application of distributed sensor systems for hydrologic data acquisition, impacts of land use change on runoff, and chemical transport in soils and streams.

Dr. Smettem is a member of the American Geophysical Union and the European Geophysical Union. He was the President of the Australian Society of Soil Science.

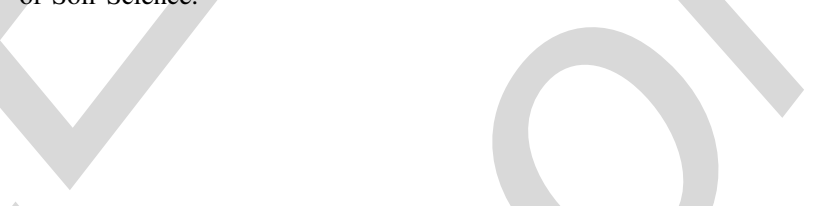

Edward G. Barrett-Lennard is currently an Associate Professor with the School of Plant Biology, University of Western Australia, Perth, WA, Australia, and also a Principal Research Officer of the Department of Agriculture and Food, Perth. He is with the Future Farm Cooperative Research Centre. His current research interests include salt tolerant perennial plants and how they can be applied to improving the capability of salt affected agricultural land.

Mr. Barrett-Lennard was a recipient of the National Dryland Salinity Program's 2002 W.E. Wood Award for excellence in salinity research and development. 


\title{
Application of Distributed Wireless Chloride Sensors to Environmental Monitoring: Initial Results
}

\author{
Nick Harris, Andy Cranny, Mark Rivers, Keith Smettem, and Edward G. Barrett-Lennard
}

\begin{abstract}
Over the next 30 years, it is anticipated that the world will need to source $70 \%$ more food to provide for the growing population, and it is likely that a significant amount of this will have to come from irrigated land. However, the quality of irrigation water is also important, and measuring the quality of this water will allow management decisions to be made. Soil salinity is an important parameter in crop yield, and in this paper, we describe a chloride sensor system based on a low-cost robust screen-printed chloride ion sensor, suitable for use in distributed sensor networks. Previously, this sensor has been used in controlled laboratory-based experiments, but here we provide evidence that the sensor will find application outside of the laboratory in field deployments. We report on three experiments using this sensor; one with a soil column, one using a fluvarium, and finally on an experiment in a greenhouse. All these give an insight into the movement of chloride over small distances with high temporal resolution. These initial experiments illustrate that the new sensors are viable and usable with relatively simple electronics, and although subject to ongoing development, they are currently capable of providing new scientific data at high spatial and temporal resolutions. Therefore, we conclude that such chloride sensors, coupled with a distributed wireless network, offer a new paradigm in hydrological monitoring and will enable new applications, such as irrigation using mixtures of potable and brackish water, with significant cost and resource saving.
\end{abstract}

Index Terms-Chloride sensor, environment, hydrology, screen-printed sensor, wireless sensor network.

\section{INTRODUCTION}

$\mathbf{O}$ NE OF the major global challenges for the next 30 years is to provide an anticipated $70 \%$ increase in food supply [1]. Various factors have an influence on this [2], but significant yield gains are achievable from improved and extended irrigation techniques. Although irrigation allows higher yields, this comes at the expense of significant water usage, as it is reported that up to $50 \%$ of irrigation water

Manuscript received June 8, 2015; revised August 25, 2015; accepted September 25, 2015. This work was supported in part by the U.K. Biotechnology and Biological Sciences Research Council, under Grant BB/J021210/1 and in part by Worldwide Universities Network. The Associate Editor coordinating the review process was Dr. Deniz Gurkan.

N. Harris and A. Cranny are with the School of Electronics and Computer Science, University of Southampton, Southampton SO17 1BJ, U.K. (e-mail: nrh@ecs.soton.ac.uk).

M. Rivers is with the Institute of Agriculture, The University of Western Australia, Crawley, WA 6009, Australia.

K. Smettem is with the School of Civil, Environmental and Mining Engineering, The University of Western Australia, Crawley, WA 6009, Australia.

E. G. Barrett-Lennard is with the School of Plant Biology, The University of Western Australia, Crawley, WA 6009, Australia.

Color versions of one or more of the figures in this paper are available online at http://ieeexplore.ieee.org.

Digital Object Identifier 10.1109/TIM.2015.2490838 is wasted [3]. Salinity of soil solution is a parameter that has a direct impact on the yield of crops [4]. If salinity can be measured at a suitable temporal resolution, then irrigation applications using mixtures of brackish water and potable water become achievable [5], with a resulting saving in potable water supplies that can then be used elsewhere, or alternatively allowing an extension of irrigated land for the same potable water usage. As an example, the irrigation system of the Harvey Irrigation Area (HIA) in Western Australia uses several reservoirs to feed the pipe network, and the water quality from each reservoir is different. Currently, water rights can be traded within the HIA via an auction-based system or, more directly, between various agricultural and nonagricultural user groups, with one of the cost factors being the required water quality. The ability to use saline water under controlled circumstances here could both optimize water usage and lower the overall cost of water. There are significant price differences for the cost of water rights depending on the source of the water and, therefore, its quality, by a factor of at least $500 \%$ between the lower quality water and the higher quality [6]. In order to start making use of this, it is necessary to develop a sensor that not only allows measurement of the salinity, but is also low cost and rugged and has low-power requirements and a useful lifetime. Such a sensor, coupled with a suitable data transport and storage system, such as a wireless sensor network [7], would allow near real-time monitoring and control (with suitable actuators) [8] of irrigated land, giving significant socioeconomic impact.

In this paper, we discuss a chloride sensor that is low cost (of the order of a euro), has a long lifetime (at least a year [9]), and is low power (it is self-generating), thus potentially meeting all of the requirements needed for deployment in a distributed sensor network. As a precursor to such a deployment, it is useful to characterize the sensor connected to more suitable portable electronics than the laboratorygrade equipment used previously and to verify that the results achieved in the laboratory can be replicated in less controlled field environments. The initial work in this paper was reported at SAS2015 in Croatia [10], but this paper extends the previous work by adding to the detail reported and also reports on a further longer term deployment in a greenhouse over a period of 12 days.

Currently, salinity measurements are usually performed by grab sampling and then analysis in a laboratory [11] or by the use of large, expensive, and isolated salinity loggers. Both of these approaches are carried out infrequently (due to cost and inconvenience) and only give a snapshot in time or 


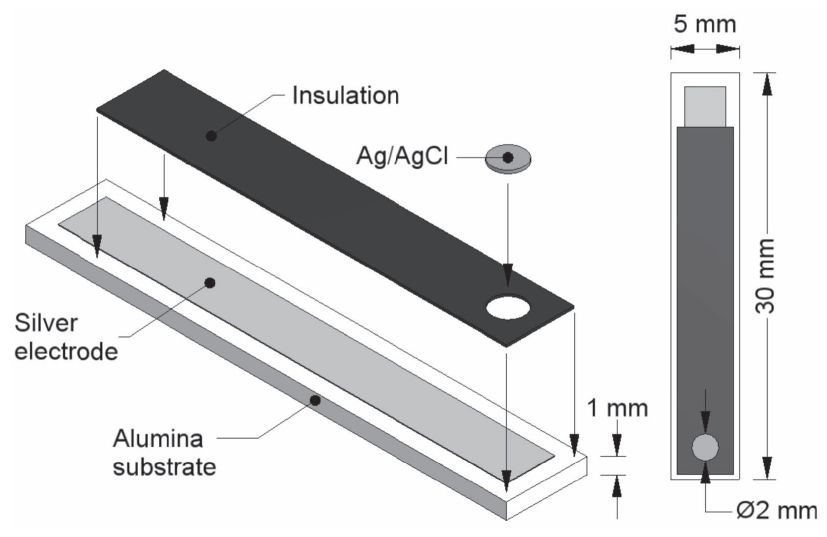

Fig. 1. Schematic showing individual layers and dimensions of a sensor.

for specific locations, potentially missing important transient or distributed events. Alternatively, conductivity can be used as a proxy for salinity [12], but this makes the assumption that the conductivity is only affected by changes in salinity, whereas in reality, there are many potential interference signals (such as application of fertilizer). Thus, there is a requirement for a low-cost salinity sensor, which would allow interesting and high-impact applications to be implemented, as in the examples above.

\section{SENSOR DESCRIPTION}

The recent work at the University of Southampton has produced a prototype sensor capable of directly measuring chloride concentrations [9]. It is a potentiometric sensor, meaning that it generates an electrical potential proportional to the local chloride concentration, making it inherently of low power consumption. It is manufactured by an industrystandard screen printing process, which makes it low cost, and it has a lifetime comparable with typical crop-growing seasons.

The sensors used for these experiments have been reported previously [9] and are undergoing continuing development with the latest generation incorporating an integrated reference electrode [13], but these were not available for the tests reported here. The sensor structure consists of a silver layer screen printed onto an alumina substrate, as shown in Fig. 1. A patterned insulating layer is then printed over the majority of the silver layer, which defines the active area of the electrode structure as well as leaving a short solderable-free end for electrical connection. In these sensors, the exposed silver layer is electrochemically chloridized to produce a silver chloride layer on top of the silver electrode, rather than screen printing a separate silver chloride layer. The resulting structure generates a potential that has a logarithmic response to chloride ion concentration. The response is governed by the Nernst equation, which predicts a theoretical sensitivity of approximately $-59.2 \mathrm{mV} / \mathrm{pCl}$ at a temperature of $298 \mathrm{~K}$, as given by

$$
E=E_{o}-0.0592 \log \left(C_{\mathrm{Cl}}\right) .
$$

Here $E$ is the measured electrode potential $(\mathrm{V}), E_{o}$ is the offset potential $(\mathrm{V})$ and $C_{\mathrm{Cl}}$ is the chloride ion

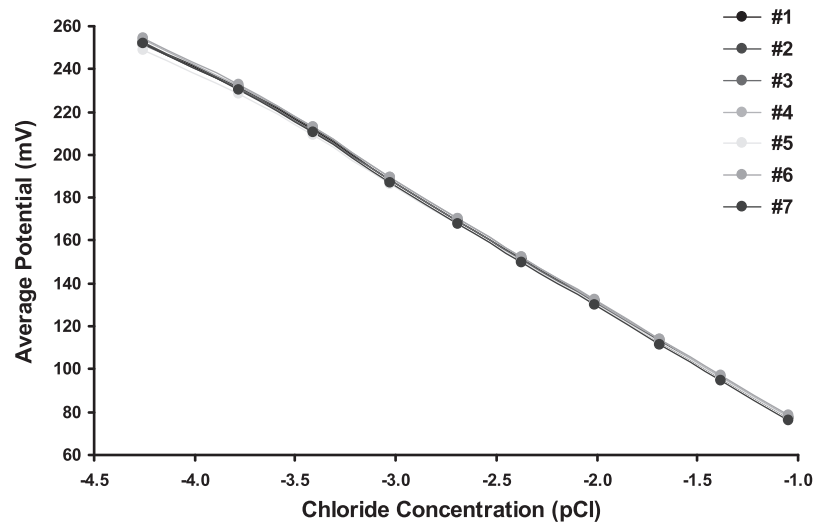

Fig. 2. Typical sensor calibration response and repeatability.

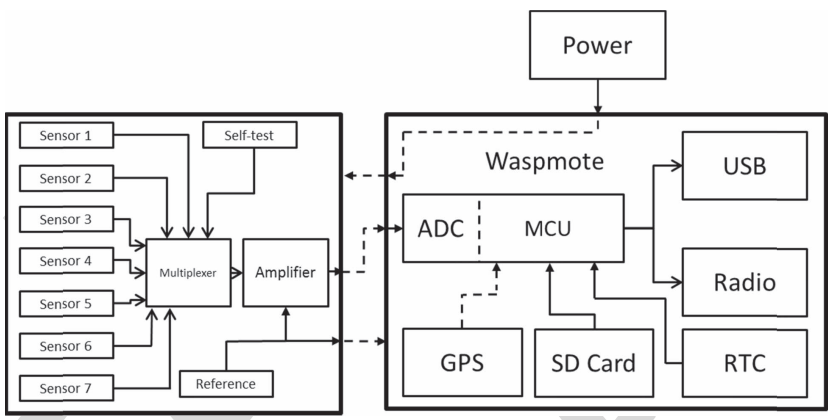

Fig. 3. Schematic showing electronics architecture.

concentration (M). Since the sensors are potentiometric, they need to be measured with respect to a reference potential. Accordingly, all measurements reported here were made with respect to a commercial $\mathrm{Ag} / \mathrm{AgCl}$ reference electrode (VWR GelPlas, $3.5 \mathrm{M} \mathrm{KCl}$ ).

The sensors were calibrated using known concentrations of potassium chloride solution and Fig. 2 shows a typical response set for a batch of seven sensors. It can be seen that the variability between sensors is very low, with sensitivities typically close to $55 \mathrm{mV} / \mathrm{pCl}$ [9]. The calibration shown in Fig. 2 was carried out at room temperature $\left(25^{\circ} \mathrm{C}\right)$, but it is noted that the response is affected by temperature. Thus, compensation was applied for the experiments reported, but it was only significant for the greenhouse experiment, since the temperature ranged between $13{ }^{\circ} \mathrm{C}$ at night to $35{ }^{\circ} \mathrm{C}$ during the day. This was done by measuring the response of the sensors when immersed in several known sodium chloride concentrations $(1000,500,250,125$, and $62.5 \mathrm{mM})$ at $25{ }^{\circ} \mathrm{C}$, and also at $50{ }^{\circ} \mathrm{C}$, and then assuming a linear regression for variation with temperature for a given chloride concentration. Air temperature in the greenhouse was available from the greenhouse monitoring system, which could then be used to index the compensation after the sensors had had their output converted from a raw voltage to a concentration.

\section{SENSOR ELECTRONICS}

The logging electronics were custom built for the sensors. The system consisted of an analog processing board, a digital 
board, and a robust water-proof housing. Fig. 3 shows the system architecture, with an analog board and a digital system. The analog board allowed up to seven individual sensors to be connected and measured against a single reference, with an 8th channel being fed with a fixed voltage to act as a form of self-test for the analog part of the system and to monitor the status of the systems power supply. Each sensor was measured individually and sequentially through an analog multiplexer. The signal was then amplified by a gain factor, which could be varied to allow for different expected dynamic ranges. The reference here is the commercial reference electrode, giving a fixed potential against which the sensor electrodes can be measured.

The digital board in this case was based on a Waspmote node, which uses an Atmel microcontroller [14], similar to an Arduino. This platform already has interfaces for common radio systems such as IEEE 802.15.4 or Global System for Mobile communication, and also has an Secure Digital (SD) card interface. Programming was done via an USB connection to a PC. The Waspmote was powered by an $1150-\mathrm{mAh}$ rechargeable battery, which in this case is recharged by connecting the system to a PC via the USB cable. The Waspmote board controlled the power to the analog board through a switched output pin and used three other pins to control the multiplexer channel selection. Data were digitized from the analog board using an on-board A/D that has a 10-bit resolution. These data were then scaled, time stamped, and then either assembled into a data packet for radio transmission or stored on the SD card. The system was sent to sleep between readings, for a predetermined length of time, depending on the application, waking up under the control of an interrupt generated by a built-in real-time clock (RTC).

Although the power consumption of the system is important, it is the sensor power consumption that is of most interest here, and the sensors themselves, being potentiometric, actually generate their own potential. The measuring system thus becomes the defining aspect and many low-power solutions are available. In this case, the Waspmote has an advertised sleep current in the extended sleep mode of $62 \mu \mathrm{A}$ and consumes $9 \mathrm{~mA}$ when active. Using peripheral functions will then add to this consumption. The measured consumption of the current system is $25 \mathrm{~mA}$ on average when logging with most of the extra current being used in writing data to the SD card and $125 \mu \mathrm{A}$ whilst asleep. Currently, the active measurement loop takes $2 \mathrm{~s}$ to complete, but this could easily be reduced as we are writing extraneous text to the memory card to aid data processing, and are also using a light-emitting diode to indicate correct operation. This gives an energy per measurement cycle of $3.3 \mathrm{~V} \times 25 \mathrm{~mA} \times 2 \mathrm{~s}=165 \mathrm{~mJ}$. It is then possible to estimate battery life assuming that all of the $1150-\mathrm{mAh}$ capacity is available. For example, continuous operation should yield a battery life of 92836 2-s cycles (or about 2.1 days) as notionally, the $3.7 \mathrm{~V}$ battery contains $3.7 \times 1.15 \times 3600=15318 \mathrm{~J}$. If the system sleeps for $5 \mathrm{~s}$ giving a duty cycle of $2 / 7$, the overall battery life is just under 7.5 days. Similarly, a sleep period of $28 \mathrm{~s}$ would give a lifetime of 30 days. Such figures were more than adequate for current testing, but future developments will continue to reduce the

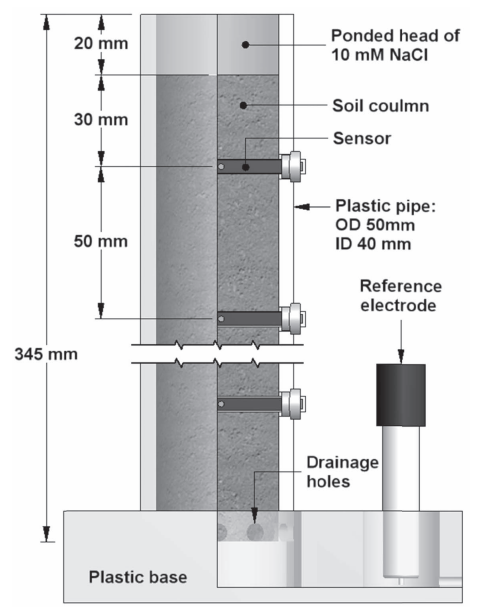

Fig. 4. Arrangement for soil column experiment (with cutaway view).

system power consumption. As sleep periods become longer, battery leakage and sleep currents become the limiting factor. The potential lifetime of a system is a function of the capacity of the energy source and the overall consumption.

For multiple data loggers operating at the same time, it was necessary to synchronize the clocks of the loggers. This was achieved by running a separate program that extracted the time from a GPS module that was temporarily installed into each logger and using this to set the RTC, with the RTC accuracy being stated as $\pm 2 \mathrm{ppm}$ or 0.16 s/day. Finally, the electronics were housed in a water-proof box, with the sensors grommeted through the casing. The sensors were on 1-mcables and so the sensing points could be up to $\pm 1 \mathrm{~m}$ away from the logger. Although it was possible to construct elaborate networks with the Waspmote, for these experiments, the system was either used as a simple remote logger or as a star network.

\section{EXPERIMENTS}

Three experiments were performed with the logger/sensor modules to establish the usefulness and practicality of being able to measure chloride at multiple points in situ:

1) single logger module with multiple sensors distributed at different depths in a soil column;

2) multiple logger modules, each with multiple sensors linearly deployed in a fluvarium;

3) single logger module installed in a practical environment (a greenhouse) to demonstrate the ability to perform longer term tests.

\section{A. Single Logger Module With Multiple Sensors Distributed at Different Depths in a Soil Column}

Although similar to work presented in [9], this experiment differs in that it demonstrates that the sensors can be used with simpler portable measuring systems, which is a step toward their use in field situations. In the previous work, a National-Instruments-based LabView system was used to $\log$ the data of the sensors. The experiment reported here is a more rigorous version and was designed to show that the system was able to perform similarly to the previous work and demonstrate the value of making real-time measurements to 


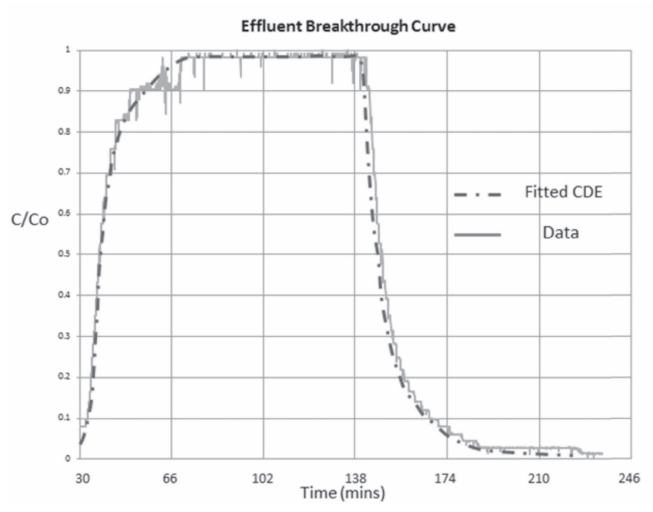

Fig. 5. Measured and predicted breakthrough curve for sensor 7 .

validate conventional modeling predictions, which will allow other situations to be modeled with confidence. It was designed to illustrate the transport of chloride though a repacked soil column under steady-state saturated flow. The experimental setup is shown in Fig. 4.

One logger was used with six sensors placed in the soil column at 50-mm vertical intervals from an initial depth of $30 \mathrm{~mm}$ from the surface and the reference located in the drainage flow. Channel 7 was at the top of the column and Channel 2 at the bottom. In this case, data were stored on the SD memory card and also sent wirelessly using IEEE 802.15.4 to a local computer for real-time monitoring through a MATLAB GUI. Sensor potentials were logged at a rate of one reading per sensor every 3 seconds, with each reading being the average of 10 successive samples.

A steady-state saturated flow regime of $510 \mathrm{mLh}^{-1}$ into a core of $1256-\mathrm{mm}^{2}$ cross section was established, giving an inflow flux of $406 \mathrm{Lh}^{-1} \mathrm{~m}^{-2}$. A ponded head of $20 \mathrm{~mm}$ was maintained at the surface with an initial background solution of $10 \mathrm{mM}$ chloride solution as $\mathrm{NaCl}$. A chloride pulse was then supplied by switching to a $100 \mathrm{mM}$ solution of $\mathrm{NaCl}$ and subsequently switching back to the $10 \mathrm{mM}$ background solution after $0.25 \mathrm{~L}$ had been supplied to the column. As an example, Fig. 5 shows the normalized measured breakthrough curve for the top sensor, together with the theoretical curve as given by convective-dispersive modeling using an updated excel version of the CXTFIT program [15]. Not only were the data well matched, but also, importantly, the mass recovery of chloride was $100 \%$ of the applied chloride.

Fig. 6 shows the results from all sensors, giving absolute concentration, and the progression and dispersion of the chloride pulse can be seen clearly. Some interesting observations can be made and most noteably that there was evidence of preferential flow pathways though the column. Some sensors did not respond in the manner that theory would anticipate, even though great care was taken in the packing of the core. It would be expected that all sensors would respond similarly, but with a time delay between them, this was not particularly evident. For example, the trace for Channel 5 (with a rapid smooth rise and a rapid fall back to background levels) shows a profile closer to that of Channel 7 (at the top of the column) than to the adjacent channels, which showed longer pulse transitions.

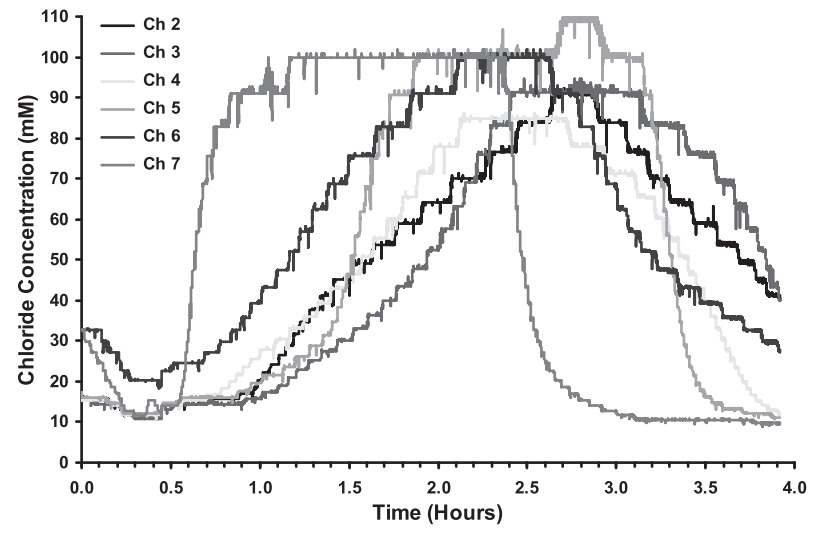

Fig. 6. Calibrated data from sensors positioned in the soil pipe.

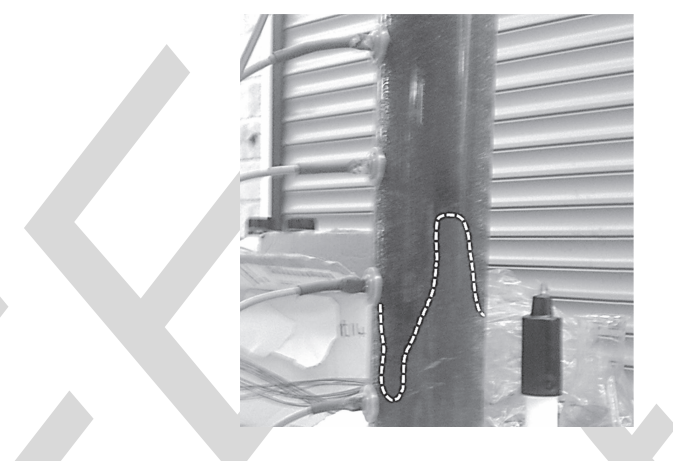

Fig. 7. Photograph of a rig showing a preferential path, enhanced by dye.

It can also be seen that Channel 4, located lower in the column, starts to respond slightly before Channel 5 , which is higher in the column. This was probably due to the presence of preferential paths for chloride movement through the column. These preferential paths were verified by separate experiments using salt pulses mixed with visible dye in a transparent column, where it was seen that different paths were apparent for salt transport and that sensors only responded when the dye-laden salt reached the sensor element. An example of the paths taken by dye laden salt can be observed in Fig. 7, where blue dye was added to the salt pulse. It can be seen that the movement through the column is uneven, despite great care being taken to pack the column. This illustrates the interesting results that these new sensors can reveal in even simple experiments such as this, and also indicates that conventional point measurement data need to be interpreted carefully.

\section{B. Multiple Logger Modules, Each With Multiple Sensors Linearly Deployed in a Fluvarium}

A fluvarium is a form of river simulator and in this case consists of a long channel $(20 \mathrm{~m})$, which had previously been filled with a stream sediment. This was used as a representative stream environment. The slope of the fluvarium was adjustable and the water flow rate could be controlled by a gated pump and measured at the outflow by the use of a flume. Fig. 8 shows a photograph of the fluvarium along its length. The sensors can be seen inserted into the river bed at 


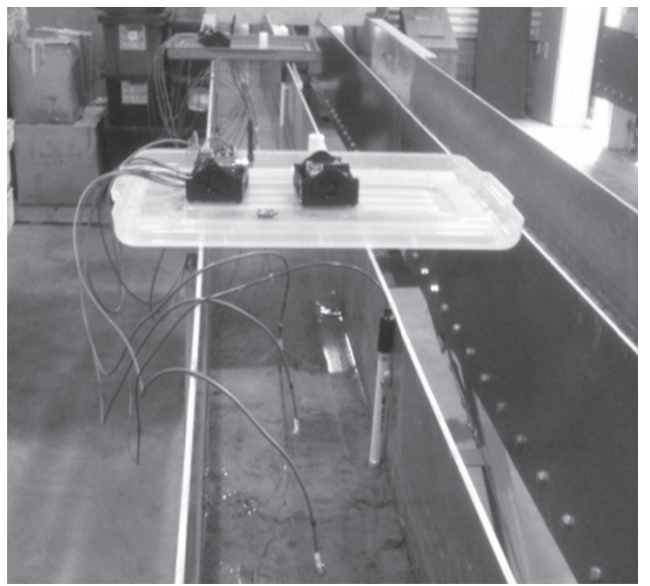

Fig. 8. Photograph showing part of the fluvarium with installed sensors.

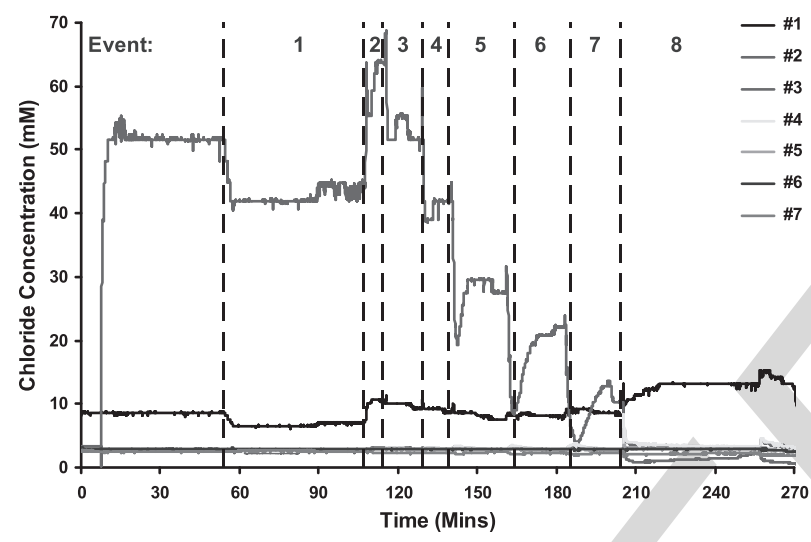

Fig. 9. Results from embedded sensors. Sensor 2 is in the inlet pool.

various locations. For the experiment reported here, the sensors were placed at $30-\mathrm{cm}$ intervals along the fluvarium length. Two sets of sensors ( 14 sensors) were used to give longitudinal measurements. A third set of sensors were colocated with the downstream sensors but were located in the surface water flow rather than being embedded in the bed sediment. The embedded sensors were inserted to a depth of $20 \mathrm{~mm}$.

The fluvarium was allowed to soak overnight in tap water with a base concentration of $10 \mathrm{mM}$ chloride solution, with no slope and no flow. A $100-\mathrm{mL}$ volume of $100 \mathrm{mM}$ chloride solution was added at the fluvarium inlet with no flow into the fluvarium, and this was allowed to pool at the inlet. A sensor (sensor 2) was placed near the downstream end of this pool as a reference, and it can be seen (Fig. 9) that the added solution was diluted by the water already in the fluvarium to give a reading of about $52 \mathrm{mM}$. The other sensors shown in Fig. 9 are those located in the river bed, moving downstream in numerical order. All of these showed very low levels of chloride, except for sensor 1, which was located very near the inlet pool. This is itself an interesting result as this is indicating that even though the river bed was wet, there was very little diffusion of chloride through the bed to the depth of the sensors over the course of the experiment, except at the point near the inlet pool. This is reasonable because the

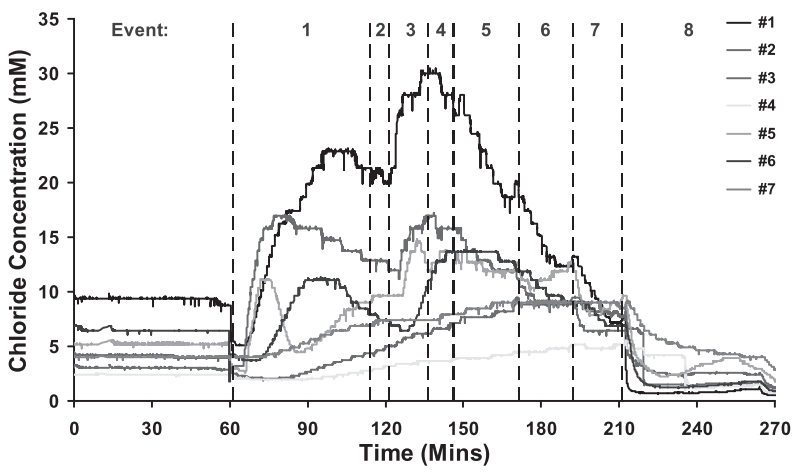

Fig. 10. Results from surface flow sensors.

TABLE I

Description OF FluVARIUM Events

\begin{tabular}{|l|l|l|}
\hline Event & Time (mins) & Description \\
\hline 1 & 54 & Fluvarium tilted \\
\hline 2 & 107 & $200 \mathrm{~mL}$ water added \\
\hline 3 & 114 & $200 \mathrm{~mL}$ water added \\
\hline 4 & 129 & $200 \mathrm{~mL}$ water added \\
\hline 5 & 139 & $400 \mathrm{~mL}$ water added \\
\hline 6 & 164 & $600 \mathrm{~mL}$ water added \\
\hline 7 & 185 & $1,000 \mathrm{~mL}$ water added \\
\hline 8 & 204 & Flume turned on \\
\hline
\end{tabular}

inlet pool was the point at which the chloride concentration was highest for longest and also the point at which there was most flow momentum as this is where new fluid was added. At about $50 \mathrm{~min}$, the gradient of the fluvarium was increased to encourage a slow drain flow away from the inlet. Periodically, samples of tap water were added to the inlet pool from a flask to provide impetus. The pulsatile nature of this method of introducing flow is apparent from Fig. 9. These events are listed in Table I.

All these events are shown in Fig. 9 and it can be seen that the sensor in the fluid in the inlet pool responded very quickly. Sensor 1 (embedded in the river bed, but nearest the inlet) also showed a small response. There was a response as the fluvarium was tilted very slightly and sensors 1 and 2 showed a decrease in concentration. This is intuitively unexpected but can be explained by the relatively poorly mixed inlet solution starting to move toward the outlet and move downstream or more local mixing of the original solution around the surface of this sensor. This movement effect is emphasized as the first volume of water was added at $107 \mathrm{~min}$. The addition of the water pushed the higher concentration further down the fluvarium as a pulse as is shown by sensor 2. Other additions are then seen to indicate a reduced concentration as the chloride volume was replaced by a more dilute solution as again pulses are pushed further down the fluvarium. These results indicate that the chloride pulse was exhibiting stop/start motion down the fluvarium under the direct influence of the addition of the extra water, as the slope was not enough to establish a meaningful flow for the volumes involved. When the fluvarium was turned on at about 200 min, a steady flow 


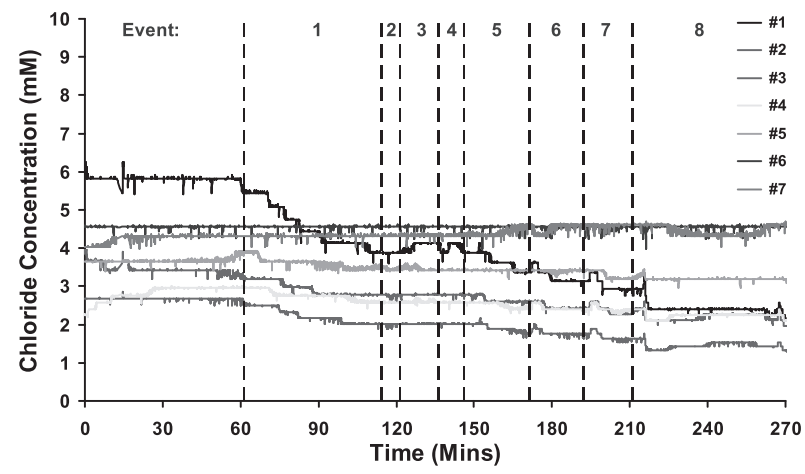

Fig. 11. Results from sensors embedded within the fluvarium sediment.

of water established itself after a few minutes and sensor 2 then showed a similar reading to the other sensors, indicating that the chloride in the inlet pool had been flushed. Sensor 1's output continued to rise as chloride was pushed or diffused through the river bed under the influence of the now constant input stream, but started to fall as the experiment finished.

Fig. 10 shows the response of the surface flow sensors located further down the fluvarium. The dotted lines show the events of Table I. The picture is less clear here. There was evidence that sensors 1,3 , and 6 were responding similarly, showing an increase in chloride concentration with time before tailing off. This is commensurated with the initial chloride pulse moving down through the surface flow of the fluvarium, being initially driven by the tilting and establishing a concentration gradient, as the sensors peaked in inverse order of distance between 60 and 100 min. Later responses were driven by the water events with a time delay, with the delay being related to distance, but it is difficult to quantify this. The other sensors responded slowly to the changing chloride environment, but correlating individual responses to a particular event is difficult.

Upon investigation, it was apparent that under these slow flow conditions, and due to the fact that the river bed in the fluvarium was not completely flat, a preferred meandering surface flow path was being established in the fluvarium. Visual inspection revealed that sensors 1,3 , and 5 were positioned in that flow. Other sensors were not in the apparent preferred flow path and so were responsive to different driving functions. A third set of colocated sensors were also measured, with these being embedded $20 \mathrm{~mm}$ deep in the river bed. This third set of sensors showed little variation from baseline over the time of the experiment, similar to sensors 3 to 7 in Fig. 9. These results are shown in Fig. 11. Although a negative result, this does show that in this river bed structure, diffusion of chloride from the flow to the bed was very slow, which in itself is an interesting result.

\section{Single Logger Module With Multiple Sensor Nodes Installed in a Practical Environment (a Greenhouse)}

In this experiment, a single logger with seven sensors was installed in a greenhouse. The seven sensors were wired to a frame and suspended in a 30-L box of sandy soil at a depth of $1 \mathrm{~cm}$, as shown in Fig. 12. One other sensor was buried to

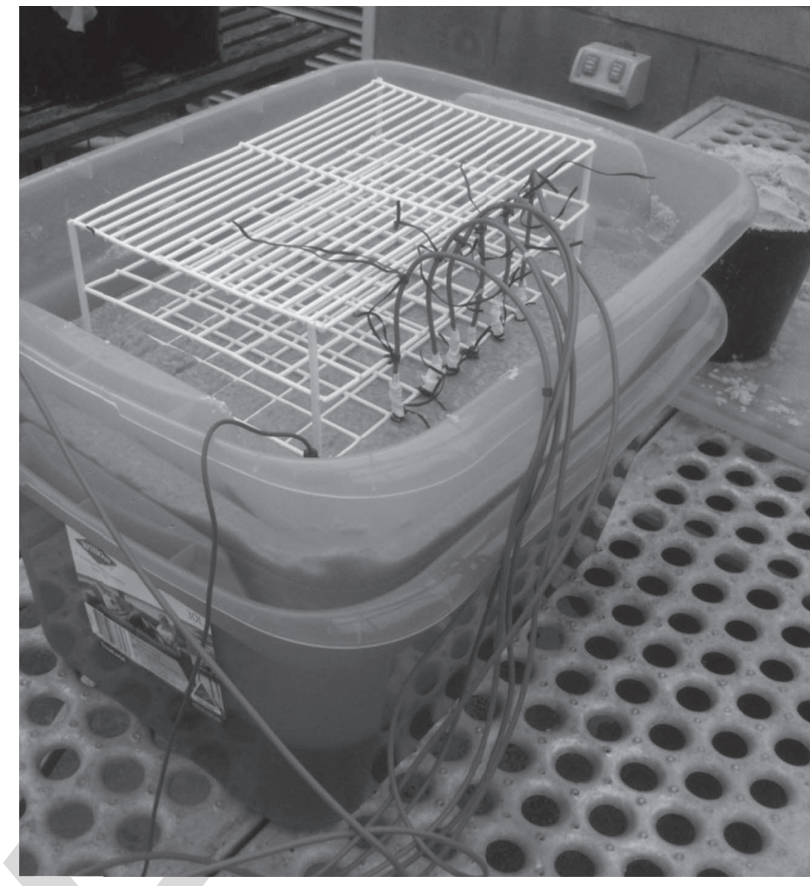

Fig. 12. Sensors mounted in a box of sandy soil in a greenhouse.

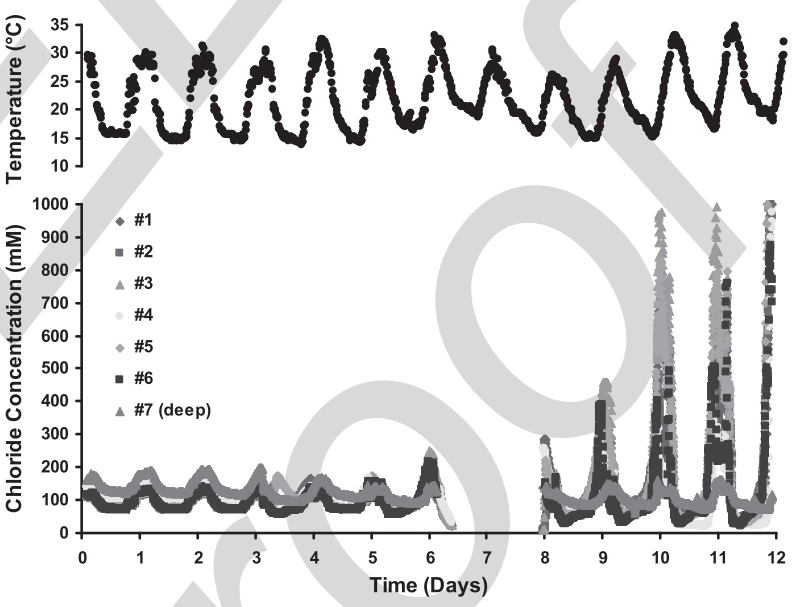

Fig. 13. Concentration data from the greenhouse mounted sensors together with ambient temperature.

a depth of $10 \mathrm{~cm}$. The box was saturated with the $100 \mathrm{mM}$ $\mathrm{NaCl}$ solution from below. Holes were drilled in the base of the box and the solution was allowed draining out. Sensors were logged at 5-min intervals. The electronics were contained in a polystyrene box to act as a temperature buffer to minimize effects of temperature on the electronic system.

The data were collected from the logger and Fig. 13 shows all the data over the duration of the experiment. It is apparent that as the soil dried out, the concentration of salt in the soil solution increased, but even over the first few days, there was a definite diurnal pattern as indicated by the ambient air temperature data. This raises the question as to whether this was a real effect or a temperature related effect, despite the temperature calibration applied. We can confirm that this was not temperature related, as an increase in temperature had 
the effect of increasing the raw sensor voltage for a given concentration, as established in our temperature calibration experiments. This implies a lower apparent concentration if no temperature compensation was applied. In our case, the raw voltage decreased with increasing ambient temperature, which would apply an error to act to reduce the apparent concentration. Thus, this diurnal variation would be de-emphasized when looking at the raw data.

With reference to Fig. 13, we can observe the definite diurnal variation though initially all traces followed the same pattern, indicating no relative difference in concentration between sensors. However, after about day 5, the shallow sensors started to deviate from the deep sensor response. At this point (day 6), the battery in the data logger failed. It was replaced two days later and the following four days show an increased divergence between the deep sensor and the shallow sensors. This corresponded to the surface soil drying out and a big increase in salt concentration in the remaining soil solution. Overnight this concentration was reduced, most likely by the capillary movement upward of moisture from deeper down or from condensation onto the surface from the atmosphere.

What is particularly marked is the rapid increase in concentration and the very large range of concentration that was possible over just a 24-h period as the soil dried out, ranging from $\sim 100$ up to $\sim 1000 \mathrm{mM}$. Once again, we can question whether this is a real effect, as the conductivity between the sensors and the reference electrode may have been affected by changes in soil moisture. Again if this was significant, it would act to reduce the apparent concentration as the voltage measured would increase. However, we actually saw a decrease in voltage measured, which implies that conductivity was still good. Thus, we can conclude that we are seeing evidence of significant variations in chloride concentration over a 24-h period, which is dependent on depth in the soil.

\section{Conclusion}

These initial trials of chloride sensors in all of these environments allow some interesting observations to be made and demonstrate the need for such sensors. First, we conclude that the sensors are usable in such environments and allow real-time measurements of chloride concentration in both fluid and wet soil environments, although significant variations in temperature do need to be compensated for. It is also apparent that calibration for absolute measurements for these sensors still requires work, but fundamentally, they operate well, and in their current state of development, they have already been providing interesting scientific data. Second, the simple experiments reported here illustrate the care needed in interpreting spot measurements in a distributed environment. Even sensors positioned a few centimeters away from a preferred flow path will give results significantly different from those obtained for sensors positioned in the preferred flow. This was evident in both the slow moving soil column experiment, where great efforts had been made to homogenize the soil packing and the more random system of the fluvarium river bed surface. This point was also emphasized in the greenhouse experiment, where the depth of the sensor was shown to be significant, as well as the relative time when the measurement was taken. This also illustrates the multiscale nature of measurements in the environment, with the surprising result that measurements can change by an order of magnitude just depending on the time of day the measurement was taken. Third, although in the fluvarium system, surface flows exhibited significant chloride concentrations, this was not necessarily evidenced even at low depths of $20 \mathrm{~mm}$ in the river bed, except very near the source of chloride. The greenhouse experiment also demonstrated the significant variation in local concentration over relatively small spatial distances.

Thus, we conclude that these chloride sensors and associated electronics offer an opportunity to measure and track shortterm chloride events in both flowing water and more static soil environments. They also offer the opportunity to measure at the same positions for longer periods of time, in contrast to the expensive, time-consuming, and often inaccurate alternative of grab sampling. The need for distributed sensors across a wide area is established and the dangers of extrapolating measurements from a point measurement are illustrated. Thus, it is concluded that these sensors, being low power and low cost, can make a significant contribution to understanding the mechanics of chloride movement though the environment and, when coupled with a distributed network, offer these results over a significant temporal and spatial scale previously unavailable.

Future work will concentrate on improving the calibration methods, particularly using the integrated technology reported in [13] and adding these sensors to a wireless network infrastructure to allow wider scale test deployments.

\section{ACKNOWLEDGMENT}

This work was funded by the UK's Biotechnology and Biological Sciences Research Council (BBSRC), grant number BB/J021210/1, and by the Worldwide Universities Network (WUN). The authors would also like to thank A. Shetta who developed the initial prototype data logger as part of his MSc degree at the University of Southampton under the supervision of N. Harris and A. Cranny.

\section{REFERENCES}

[1] FAO. (2009). How to Feed the World in 2050. [Online]. Available: http://www.fao.org/fileadmin/templates/wsfs/docs/expert_paper/How_to _Feed_the_World_in_2050.pdf, accessed Aug. 10, 2015.

[2] N. D. Mueller, "Closing yield gaps through nutrient and water management," Nature, vol. 490, no. 7419, pp. 254-257, 2012.

[3] M. Rivers, N. Coles, H. Zia, N. R. Harris, and R. Yates, "How could sensor networks help with agricultural water management issues? Optimizing irrigation scheduling through networked soil-moisture sensors," in Proc. IEEE Sensors Appl. Symp., Zadar, Croatia, Apr. 2015, pp. 1-6.

[4] N. Katerji, J. W. van Hoorn, A. Hamdy, and M. Mastrorilli, "Salinity effect on crop development and yield, analysis of salt tolerance according to several classification methods," Agricult. Water Manage., vol. 62, no. 1, pp. 37-66, 2003.

[5] J. D. Rhoades, "Use of saline water for irrigation," California Agricult., vol. 38, no. 10, pp. 42-43, Oct. 1984. [Online]. Available: https://ucanr edu/repositoryfiles/ca3810p42-72379.pdf, accessed Sep. 28, 2015.

[6] Harvey Water Water Trading. [Online]. Available: http://www.harveywater.com.au/water_trading.asp?watertradingid=5, accessed Sep. 28, 2015.

[7] Aqeel-ur-Rehman, A. Z. Abbasi, N. Islam, and Z. A. Shaikh, "A review of wireless sensors and networks' applications in agriculture," Comput. Standards Interfaces, vol. 36, no. 2, pp. 263-270, 2014. [Online]. Available: http://dx.doi.org/10.1016/j.csi.2011.03.004 
[8] H. Zia, N. R. Harris, G. V. Merrett, M. Rivers, and N. Coles, "The impact of agricultural activities on water quality: A case for collaborative catchment-scale management using integrated wireless sensor networks," Comput. Electron. Agricult., vol. 96, pp. 38-126, Aug. 2013.

[9] A. Cranny, N. R. Harris, M. Nie, J. A. Wharton, R. J. K. Wood, and K. R. Stokes, "Screen-printed potentiometric $\mathrm{Ag} / \mathrm{AgCl}$ chloride sensors: Lifetime performance and their use in soil salt measurements," Sens. Actuators A, Phys., vol. 169, no. 2, pp. 288-294, Oct. 2011.

[10] N. Harris, A. Cranny, M. Rivers, and K. Smettem, "Applications of a wireless chloride sensor in environmental monitoring," in Proc. IEEE Sensors Appl. Symp., Zadar, Croatia, Apr. 2015, pp. 1-5.

[11] D. L. Corwin and S. M. Lesch, "Protocols and guidelines for fieldscale measurement of soil salinity distribution with ECa-directed soil sampling," J. Environ. Eng. Geophys., vol. 18, no. 1, pp. 1-25, 2013.

[12] D. L. Corwin and S. M. Lesch, "Apparent soil electrical conductivity measurements in agriculture," Comput. Electron. Agricult., vol. 46, nos. 1-3, pp. 11-43, Mar. 2005.

[13] A. Cranny, N. R. Harris, and N. M. White, "Screen-printable porous glass: A new material for electrochemical sensors," J. Mater. Sci., Mater Electron., vol. 26, no. 7, pp. 4557-4564, Jul. 2015.

[14] Libelium. Libellium Website. [Online]. Available: http://www.libelium.com/products/waspmote/, accessed Oct. 22, 2015.

[15] N. Toride, F. J. Leij, and M. T. Van Genuchten, "The CXTFIT code for estimating transport parameters from laboratory or field tracer experiments," U.S. Salinity Lab., United States Dept. Agricult., Agricult. Res. Service, Riverside, CA, USA, Res. Rep. 137, Version 2.0, 1995.

Nick Harris received the Ph.D. degree from the University of Southampton, Southampton, U.K., in 1997.

$\mathrm{He}$ is currently an Associate Professor with the Department of Electronics and Computer Science, University of Southampton. He is the Co-Founder of Perpetuum Ltd., Southampton, the world's leading vibration energy harvesting company. He has authored over 180 publications and patents in electrochemical sensors, wireless sensor networks, biosensors, energy harvesting, microfluidic systems, and microsystem process development. His current research interests include machine-leaning approaches for distributed sensor systems, ion-selective electrochemical sensors, and novel environmental energy harvesters.

Dr. Harris is a member of the Institution of Engineering and Technology, a Chartered Engineer, and the Director of ECS Partners.

Andy Cranny received the Ph.D. degree in electronics and computer science from the University of Southampton, Southampton, U.K., in 1992.

$\mathrm{He}$ is currently a Senior Research Fellow with the Faculty of Physical Sciences and Engineering, University of Southampton. His current research interests include the development of environmental sensors and the development of autonomous systems for home-based physical rehabilitation.
Mark Rivers is currently a Research Professor with the Institute of Agriculture, University of Western Australia, Crawley, WA, Australia, and the Director of ClearWater Research and Management Pty. Ltd., Mandurah, WA, Australia. His principal areas of expertise lie in developing the relationships between land management practices and catchment water quality. The majority of his professional experience has been gained working within threatened ecosystems prone to eutrophication and toxic algal blooms. He has extensive experience in the development of environmental risk scenarios and on the analysis of the likely environmental, social, and economic effects of adverse impacts on major water bodies.

Mr. Rivers is a member of the Environment Institute of Australia and New Zealand, a Qualified Lead Auditor of Environmental Management Systems, and a Certified Environmental Practitioner. He has represented the state of WA at senior diplomatic-level meetings concerning water quality protection in Turkey, Italy, U.K., and the USA.

Keith Smettem received the Ph.D. degree from Sheffield University, Sheffield, U.K., in 1982.

$\mathrm{He}$ is currently a Professor of Environmental Engineering with the Department of Civil, Environmental and Mining Engineering, University of Western Australia, Crawley, WA, Australia. He has authored over 200 publications and patents in hydrology, soil physics, plant water relations, and environmental engineering. His current research interests include ecohydrologic responses to climate change, development of woody perennial feedstocks for bioenergy generation, development of field methods for measurement of soil physical properties, application of distributed sensor systems for hydrologic data acquisition, impacts of land use change on runoff, and chemical transport in soils and streams.

Dr. Smettem is a member of the American Geophysical Union and the European Geophysical Union. He was the President of the Australian Society of Soil Science.

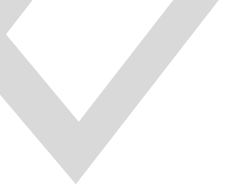

Edward G. Barrett-Lennard is currently an Associate Professor with the School of Plant Biology, University of Western Australia, Perth, WA, Australia, and also a Principal Research Officer of the Department of Agriculture and Food, Perth. He is with the Future Farm Cooperative Research Centre. His current research interests include salt tolerant perennial plants and how they can be applied to improving the capability of salt affected agricultural land.

Mr. Barrett-Lennard was a recipient of the National Dryland Salinity Program's 2002 W.E. Wood Award for excellence in salinity research and development. 